\title{
La construcción del narrador en la crónica periodística. Análisis de los textos de Alejandro Almazán*
}

\author{
The construction of the narrator in newspaper articles. Analysis \\ of Alejandro Almazán's texts
}

Jeovanny Benavides Bailón ${ }^{* *}$

\begin{abstract}
RESUMEN
La construcción del narrador en la crónica es un estudio que describe cómo esta figura es elaborada en los textos periodísticos. Para ello se realiza un análisis de las piezas de no ficción del autor mexicano Alejandro Almazán. De esta manera, se parte del hecho de que el narrador no solo es una prerrogativa de la literatura, sino que también se encuentra presente en el periodismo. Para ello, se propone un análisis de carácter cualitativo haciendo especial énfasis en el sentido textual de las crónicas seleccionadas y abordadas mediante los enfoques teóricos de Saavedra (1999), Genette (1989) y Friedman (1975). Estos aportes críticos provenientes de los estudios literarios evidencian que existe un vacío por parte de las investigaciones periodísticas que, en su mayor parte, se han quedado en los manuales de redacción y no han indagado en aspectos fundamentales del enfoque disciplinar periodístico. El resultado de este trabajo es retomar la discusión acerca de la construcción del narrador en este tipo de textos y dejar en evidencia que esta figura es la primera que se construye en cualquier relato, no solo en el ámbito de la ficción. Las conclusiones señalan que las crónicas de Alejandro Almazán son significativas para el análisis del rol que cumple el narrador en un género como la crónica.
\end{abstract} Palabras clave: autor, crónica, narrador, periodismo, relato.

Este artículo se inscribe en el Proyecto de Investigación Posdoctoral del Instituto de Estudios Latinoamericanos de la Freie Universität Berlín (Alemania) denominado "La configuración de la crónica periodística como relato histórico de las dictaduras, narcoguerrillas y conflictos en América Latina. Análisis de los casos de México, Argentina, Chile y Colombia".

* Ecuatoriano. Doctor en Comunicación de la Universidad Nacional de La Plata (Argentina). Académico de la Universidad Técnica de Manabí (Ecuador) y de la Pontificia Universidad Católica del Ecuador. Portoviejo, Ecuador. jeovanny.benavides@utm.edu.ec 


\section{SUMMARY}

The construction of the narrator in newspaper reports is a study that describes how the narrator is developed in journalistic texts. For this purpose, an analysis of the non-fiction writing of Mexican Keywords: author, report, narrator, journalism, story. author Alejandro Almazán was carried out. It is based on the fact that the narrator is not only a prerogative of literature, but is also a journalist. To do this, we proposed a qualitative analysis, with special emphasis on the textual meaning of the articles that were selected and addressed using the theoretical approaches of Saavedra (1999), Genette (1989) and Friedman (1975). This literary analytical approach showed there is a gap in journalistic investigations that, for the most part, have remained in writing manuals and have not investigated fundamental aspects of the journalistic disciplinary approach. The work concluded that there is scope for starting a discussion about the construction of the narrator in journalistic texts and proves that the narrator is the first character that is constructed in any story, not only in the field of fiction. The research showed that there are significant grounds for analyzing Alejandro Almazán's articles in terms of the role played by the narrator in a genre such as the newspaper report. 


\section{Introducción}

\section{La configuración de una voz}

¿Quién habla y cómo se configura la voz narrativa en los textos periodísticos? Por mucho tiempo el tema pasó prácticamente inadvertido. Los abordajes teóricos tradicionales de los estudios de esta disciplina (Gargurevich, 1982; Grijelmo, 1997), por ejemplo, no han diferenciado entre las figuras de autor y narrador, o han asumido de forma implícita que se trata de lo mismo. Luego, cuando el periodismo tomó prestado de la literatura recursos estilísticos y de composición en géneros como el reportaje y, principalmente, la crónica, también se vio la necesidad de visibilizar y de construir al narrador igual que ocurre en los cuentos y las novelas. En ese sentido, el propósito de este trabajo apunta a determinar quién dice lo que dice en los escritos periodístico-literarios; particularmente, en las crónicas del periodista mexicano Alejandro Almazán.

Cuando surgieron movimientos que pretendieron eclosionar las formas convencionales de escritura periodística y los modos de ejercer la reportería, tipo el Nuevo Periodismo propuesto por Wolfe (1976), en las décadas de 1960 y 1970, la mirada apuntaba hacia la teoría que se había elaborado hasta entonces en los manuales del oficio; sin embargo, estos textos se circunscribían a detallar lo más artesanal de la profesión: cómo hacer una noticia, una entrevista o a lo mucho se dedicaban a explicar el erosionado enfoque de la pirámide invertida. Por ello, el periodismo - que empezaba a enriquecerse con recursos estilísticos y procedimientos narrativos-, tuvo que amparar su orfandad teórica en los estudios literarios.

Se debe considerar en este punto que en el ámbito latinoamericano, la crónica ha tenido un rol esencial en la historia de la literatura de la región. Desde la llegada de los cronistas de indias, que poblaron el continente con la llegada de los colonizadores a fines del siglo $\mathrm{XV}$ e inicios del siglo XVI, este género se ha convertido en "La matriz de uno de los modos de contar la realidad social latinoamericana" (Falbo, 2007, p. 15). Algunos de los más representativos cronistas de Indias fueron Fray Bartolomé de las Casas, Fray Pedro Simón, Fray Bernardino de Sahagún, el inca Garcilaso de la Vega y Bernal Díaz del Castillo, entre otros. 
Sin embargo, el desarrollo de este género, con algunos de los rasgos con los que cuenta en la actualidad, tiene un resurgir en el modernismo. De hecho, autores como Rotker (1992) argumentan que la crónica en América Latina surgió en la modernidad, a fines del siglo XIX cuando este movimiento pretendió unir formas diversas y aplicar la dualidad como sistema, la escritura como tensión y punto de encuentro entre antagonismos: prosa y poesía, la literatura y el periodismo. De ahí que en esta época, múltiples autores empezaron a dejar de propagar en sus escritos las causas y motivaciones ideológicas y partidistas y comenzaron a elaborar un discurso narrativo propio basado en la preocupación por la realidad social y detallarla bajo el paraguas de la crónica periodística, que iba más allá del "relato objetivo" que pretendía la noticia convencional. Basta con echar una mirada a los cultores de este género en el modernismo para destacar que los intentos por consolidar la crónica se realizaban en serio: José Martí, Rubén Darío y Manuel Gutiérrez Nájera.

Tanto los cronistas de Indias como los cronistas del modernismo empezaron a visibilizar este género y a generarle un espacio en el ámbito periodístico y literario. Para Rotker (1992), la publicación de estos primeros textos evidencia que América Latina se hizo amparándose en las crónicas, porque sus principales exponentes se esforzaron por preservar la memoria histórica. El cronista dejó de ser el profesional que se caracterizaba por ser una caja de resonancia de sus fuentes de información que exigía el periodismo ortodoxo y comenzó a generar un juicio crítico desligado de posturas ideológicas respecto de los hechos, imponiendo sus perspectivas e involucrando elementos literarios en los que se demostraba su preocupación por la dimensión estética del texto. Con ello, queda claro que el cronista tiene una voz propia para abordar los diversos hechos que cuenta y puede ser irónico, sarcástico, analítico, descriptivo y con una perspectiva narrativa honesta.

Los temas tratados por la crónica también muestran su sello latinoamericano. Aparte de recrear subjetivamente los hechos, este género se caracteriza por entretejer lazos y profundos vínculos con sus lectores. Para Falbo (2007), las grandes enfermedades, la opresión del Estado, las guerrillas y las invasiones - narrativas que persisten en un rasgo de la crónica y que se puede rastrear desde la conquista hasta el 
presente- son versiones de la realidad que ponen en conflicto la versión hegemónica de las sociedades que cuentan.

En este contexto, la crónica cuenta con una larga tradición en América Latina y que ha estado enmarcada en la hibridez y mixtura disciplinar conocida como periodismo literario. $Y$ es en este sentido en el que surge la relevancia de abordar la construcción del narrador en los textos de no ficción. Para entender los alcances de la elaboración de esta figura analizamos, en primer lugar, el pertinente enfoque de varios estudios en torno al tema.

\section{La perspectiva clásica del punto de vista}

Para ser claros y no caer en ambigüedades posteriores empezaremos por explicar lo obvio: el autor-cronista es la persona de carne y hueso que emprende la elaboración de un texto periodístico. Es, por tanto, quien vive en el mundo real y quien posee necesidades como todos los seres humanos. En su empeño por crear una crónica este profesional apela a la construcción de un narrador periodístico-literario quien será la voz que guíe y oriente al lector.

Para indagar en la construcción de esa figura analizaremos en primer lugar el problema del punto de vista, un aspecto que necesariamente aborda la situación narrativa del universo textual. Solo en este sentido, y al narrativizar el discurso original de una fuente determinada, se puede dar cuenta de los pensamientos, emociones o estados de conciencia de los personajes que surjan en el relato periodístico.

Este proceso ha sido descrito por varios investigadores. Uno de ellos es Saavedra Vergara (1999) quien explica que son seis los elementos que configuran la situación narrativa. Los primeros cinco aspectos los rescata del crítico norteamericano Turco (1989), mientras que el aspecto restante lo toma de Genette (1989). Como se verá a continuación, la tipología que presentamos procede de los estudios literarios y con ella se determinan las condiciones de los narradores construidos en géneros como la crónica. La clasificación es la que sigue:

a) Orientación. Aquí se contemplan dos posibilidades principales: la de narrador, no identificado, que cuenta la historia desde afuera; y la de personaje, aquí quien narra es el protagonista, el antagonista o un personaje secundario. 
b) Persona gramatical: primera, segunda, tercera, ya sea singular o plural. Esta elección tiene consecuencias para las posteriores decisiones en el relato.

c) Aspecto: se trata de un narrador que tiene acceso exterior y que solo da cuenta de las acciones de los personajes, sin intervenir; también puede presentarse el aspecto de la reflexión, aquel que se obtiene de los sentimientos y pensamientos que tiene el narrador respecto de sus personajes y de las situaciones que conforman la historia.

d) Ángulo: en el ángulo simple, se siguen las acciones de un personaje y solo se narra lo que él presencia. En el ángulo múltiple se narra lo que ocurre en presencia de dos o más personajes. Y en el ángulo omnipresente, el narrador puede estar en todos los lugares necesarios para el relato, incluso simultáneamente.

e) Acceso: el narrador puede tener solo acceso exterior a los acontecimientos observables por cualquier ser humano; o interior, es decir, además puede conocer y narrar los pensamientos y sentimientos de los personajes.

f) Tiempo de la narración: ulterior, para aquellas narraciones posteriores a los acontecimientos relatados; anterior o relato predictivo; simultáneo, contemporáneo a la acción; e intercalado, entre los momentos de la acción.

A través de estas categorías se cubren todas las posibilidades que podría adoptar un enfoque sobre el punto de vista. En primer lugar, cuenta con la configuración de un narrador omnisciente, que tiene una visión por detrás, es decir que conoce absolutamente todo sobre lo que acontece en la historia. Además cuenta con la narración desde la perspectiva de un personaje y, por último, esta tipología tiene una visión desde fuera, donde hay un narrador que se convierte en un observador de los hechos.

Para Saavedra Vergara (1999), estos aspectos y rasgos dispuestos en un texto periodístico literario contribuyen a ampliar notoriamente las prerrogativas cognoscitivas del narrador periodístico, de tal forma que en la construcción textual puede acceder a los estados de conciencia más íntimos de sus personajes.

Como indicamos anteriormente, en el momento de leer un texto narrativo hay un narrador que relata una historia y que asume un pun- 
to de vista mientras va narrando. Para Genette (1989), el punto de vista estaría en los elementos de ángulo y acceso y sistematiza este fenómeno en lo que él denomina "focalización" y a la que le brinda la siguiente tipología.

a) Focalización cero: se caracteriza porque nunca se indica el punto de vista de los personajes.

b) Focalización interna: es cuando corresponde a los personajes. La narración es hecha desde adentro de la historia, en cuyo caso el narrador es un personaje de la misma, pudiendo ser un protagonista o un personaje secundario. Puede ser fija si todo está visto por un solo personaje; variable si el personaje focalizador varía según episodios; o múltiple, si un mismo acontecimiento es visto por distintos personajes.

c) Focalización externa: el focalizador es un agente que está fuera de la historia. Los personajes actúan ante el narrador y la narración es presentada desde afuera de la historia. En tal caso, el narrador no forma parte de la trama, sino que se ubica fuera de los personajes y fuera de los sucesos y, por eso, narra en tercera persona.

Cuando se alude a la focalización inevitablemente se designa al lugar o la persona desde cuya perspectiva transcurre la narración. En el caso de la no ficción las preguntas que surgen son: ¿Cómo se narran los géneros periodísticos-literarios? ¿Quién los narra? ¿Qué antecedentes tiene esta narración y qué valor dentro de su contexto histórico y social? En este estudio analizamos la forma en que el narrador construido por el cronista puede manejar estos criterios.

En este sentido también se considera que el punto de vista se encuentra estrechamente relacionado con la tipología del narrador que se decida utilizar en la historia. Una de las clasificaciones más aceptadas al respecto es la que brinda Friedman (1975) a continuación:

a) Omnisciencia editorial: el narrador se inmiscuye en la historia.

b) Omnisciencia neutral: el narrador utiliza la tercera persona de un modo impersonal, no interviene directamente.

c) El yo como testigo: un personaje narra en primera persona, apenas conoce los pensamientos de los demás personajes. 
d) El yo como protagonista: también llamado narrador protagonista. Habla de sus pensamientos, etc.

e) Omnisciencia multiselectiva: la historia llega directamente a través de la conciencia de los personajes, no hay narrador.

f) Omnisciencia selectiva: el punto de vista gira en torno a un único personaje.

g) Modo dramático: se suprime el narrador. El lector debe deducir lo que piensan los personajes por sus palabras y gestos. Se busca objetividad absoluta.

h) Cámara: se intenta presentar una historia tal como lo haría una cámara fotográfica.

La variedad de puntos de vista dota e impregna a la historia de una gran riqueza narrativa. En la propuesta de Friedman (1975) hay una diferencia sustancial en los criterios que hemos venido manejando acerca de las concepciones de autor y narrador. El primero tiene la facultad de emitir criterios y reflexiones en el transcurso de la historia y eso se puede apreciar en la omnisciencia editorial. Por ello, en las cinco tipologías restantes quien habla en la historia es el narrador. En los últimos aspectos, el narrador debe desaparecer para que hablen íntegramente los personajes como si se tratara de la expectación de una obra de teatro. Podemos apreciar que en los dos primeros aspectos, el narrador está construido para que pueda reflexionar respecto de la historia. Se trata de comentarios que están generalmente en tercera persona. En ambas tipologías hay una orientación del narrador con ángulo omnipresente y acceso interior.

En la categoría de yo como testigo quien narra es un personaje secundario y lo hace en primera persona. El yo como protagonista, en cambio, cuenta, al igual que el aspecto anterior, ángulo simple o múltiple y acceso exterior, la diferencia radica en que el lector puede conocer qué sucede en la conciencia del personaje principal. Además en estos dos casos puede darse la posibilidad de construir un narrador coral, ya que presenta desde un ángulo múltiple. Las omnisciencias múltiples y selectivas no poseen comentarios editoriales, pero tienen acceso interior y pueden narrarse en primera, segunda o tercera persona. En lo que respecta al modo dramático y a la cámara, su principal característica es la construcción de diálogos. Según Friedman (1975), 
supuestamente el narrador desaparece en estos dos últimos aspectos. No obstante, consideramos que esto es una impresión errónea, porque el narrador nunca desaparece, no puede, solo finge estar ausente.

Otra tipología del narrador la brinda el mismo Genette (1989) y es esta:

a) Autodiegéticos: es quien relata experiencias como si fuera un personaje central y se encuentra en un momento posterior a la historia.

b) Homodiegéticos: es quien participa en la historia y la narra al mismo tiempo.

c) Heterodiegéticos: se trata de un narrador que se encuentra fuera del relato y no participa en la historia. Aquí se pueden encontrar rasgos de omnisciencia.

De acuerdo con Chatman (1990), al relatarse una percepción se presupone necesariamente otro acto de observación con un punto de vista independiente, es decir, el del narrador. Así se concluye que el narrador ya no percibe, sino que concibe. Este es un criterio fundamental en el relato. Por ello es clave diferenciar en el texto periodístico que el autor y el narrador no son lo mismo. El mundo narrado está integrado por la historia y el discurso, mientras que el acto de la narración propiamente dicho es asumido por el narrador. Estos tres elementos (historia, discurso y narración) están estrechamente vinculados. De esta forma, en un relato el narrador es la voz que construye el mundo y se convierte en alguien que media entre ese mundo y el lector, porque, según Stanzel (1984), "la mediación es la característica genérica que distingue la narración de otras formas de arte literario” (p. 5). Por ello, el narrador periodístico-literario es una figura que se constituye en tanto y en cuanto es un enunciador de un acto discursivo.

En este contexto, Ricoeur (2005) señala que el narrador se enmarca en lo que denomina el dador del relato, proceso en el que distingue tres definiciones esenciales: el relato emitido por una persona, el relato que concibe al narrador y le otorga dotes de omnisciencia total y el relato en el que solo se puede conocer la perspectiva de un determinado personaje. Por ello, y en definitiva, tratamos de rescatar en este entramado teórico la concepción de Barthes et al. (1998) de que bajo ningún criterio se debe confundir el autor material de un relato con el narrador de ese texto; para ello, este autor expresa un razonamiento 
decisivo en este estudio: "Quien habla (en el relato) no es quien escribe (en la vida) y quien escribe no es quien existe" (p. 34).

En el abordaje de estas perspectivas teóricas es pertinente destacar el estudio de Hoyos (2003) sobre el periodismo literario. Según este autor, la figura del narrador es fundamental para contar una historia y para ello es necesario que se desarrolle un proceso de inmersión, de tal manera que el relato tenga la capacidad de narrar la vida en toda su complejidad y el texto periodístico pueda leerse como una buena novela. Para que ello ocurra es importante que el autor asuma la construcción de un narrador que destaque las emociones de los personajes y sus características tanto físicas como psicológicas. En ese sentido, la crónica necesita un narrador que sepa reemplazar la mera narración histórica basada en el resumen y dote a sus textos con un efecto de verosimilitud que sea capaz de motivar al lector comenzar una historia y no detenerse sino hasta el punto y final.

Otro estudioso del periodismo literario que ha dejado su impronta en géneros como la crónica ha sido Chillón (1999). Para este autor, la figura del narrador es relevante en la medida en que se constituye en una alternativa viable para capturar la calidad de la experiencia de los individuos. Pese a ello se debe considerar en todo momento que se trata de periodismo y, aunque se emplee cualquier figura o técnica propia del ámbito literario, no deben inmiscuirse elementos ficticios.

De todas las vocaciones del hombre, el periodismo es aquella en la que hay menos lugar para las verdades absolutas. La llama sagrada del periodismo es la duda, la verificación de los datos, la interrogación constante. Allí donde los documentos parecen instalar una certeza, el periodismo instala siempre una pregunta. Preguntar, indagar, conocer, dudar, confirmar cien veces antes de informar: esos son los verbos capitales de la profesión más arriesgada y más apasionante del mundo (Martínez, 1997).

De este modo, autores como Benavides (2016) dejan claro que la configuración del tipo de narrador determina la forma de ver el mundo por parte de un autor. En el relato periodístico la narración se hace a través de la perspectiva del narrador, porque es la primera persona que crea el autor. Por ejemplo, el periodista literario escribe acerca de temas comunes en los cuales busca un grado de identificación con su 
historia y con los personajes, para transmitir justamente esa identificación en el transcurso de la narración. Además, adquiere un compromiso con el lector para intentar transmitir una mirada honesta respecto del relato que cuenta, se introduce en la historia de los personajes e investiga el contexto en el que se desarrollaron los acontecimientos. Por ello, el autor elige situarse en un lugar determinado para configurar su punto de vista.

Los enfoques teóricos expuestos, tomados todos de los estudios literarios, sirven para abordar la construcción del narrador en la crónica periodística contemporánea. No se trata en ningún caso de una revisión exhaustiva, pero sí es significativa, útil y pertinente para explicar el propósito de este trabajo. Es de destacar que investigaciones como las de Aguilar (2018) y Puerta (2016) han tratado esta problemática y sus fenómenos.

\section{Metodología}

El abordaje metodológico de este estudio se basa inicialmente en una revisión bibliográfica de los trabajos e investigaciones que aportan luces y fundamentos teóricos a la construcción del narrador de no ficción. Por ello, hemos acudido a revisiones y aportes de los estudios literarios clásicos, si puede decirse. Adicionalmente a ello, y para realizar un complemento a lo teórico, proponemos un análisis textual de carácter cualitativo, pues es una técnica que hace hincapié en el sentido del texto. A criterio de Vasilachis (2006), este enfoque es riguroso y flexible, pues se basa en la interpretación. Según Rossman y Rallis (1998), este tipo de análisis es sistemático por cuanto aborda categorías predeterminadas. En el caso de este trabajo, las categorías son los tipos de narradores utilizados en seis textos seleccionados del cronista mexicano Alejandro Almazán. Escogimos a este autor y a sus crónicas porque son representativas y ejemplares para evidenciar la construcción narrativa a la que hemos hecho referencia. En la siguiente tabla se sistematiza el análisis de los textos mencionados y para ello se han considerado, como puede apreciarse, las tipologías de narrador y punto de vista expresados en el apartado anterior. 
Tabla 1

Tipología del narrador y el punto de vista en las crónicas seleccionadas

\begin{tabular}{|c|c|c|c|c|}
\hline $\begin{array}{l}\text { Narrador y } \\
\text { punke de vista } \\
\text { Crónicas de } \\
\text { Alejandro } \\
\text { Almazán }\end{array}$ & $\begin{array}{l}\text { La situación } \\
\text { narrativa, } \\
\text { según Saavedra } \\
\text { Vergara (1999) }\end{array}$ & $\begin{array}{l}\text { El punto } \\
\text { de vista y } \\
\text { focalización, } \\
\text { según Genette } \\
\text { (1989) }\end{array}$ & $\begin{array}{l}\text { La tipología del } \\
\text { narrador, según } \\
\text { Friedman } \\
\text { (1975) }\end{array}$ & $\begin{array}{l}\text { La tipología del } \\
\text { narrador, según } \\
\text { Genette (1989) }\end{array}$ \\
\hline $\begin{array}{l}\text { Carta desde } \\
\text { La Laguna }\end{array}$ & $\begin{array}{l}\text { Empleo de } \\
\text { la segunda } \\
\text { persona y } \\
\text { ángulo simple }\end{array}$ & $\begin{array}{l}\text { Focalización } \\
\text { interna }\end{array}$ & $\begin{array}{l}\text { Omnisciencia } \\
\text { selectiva }\end{array}$ & Autodiegético \\
\hline $\begin{array}{l}\text { Los Acapulco } \\
\text { Kids }\end{array}$ & $\begin{array}{l}\text { Empleo de } \\
\text { la primera } \\
\text { persona y } \\
\text { ángulo simple }\end{array}$ & $\begin{array}{l}\text { Focalización } \\
\text { interna }\end{array}$ & Yo como testigo & Homodiegético \\
\hline $\begin{array}{l}\text { Lino Portillo, } \\
\text { asesino a } \\
\text { sueldo }\end{array}$ & $\begin{array}{l}\text { Empleo de la } \\
\text { tercera persona } \\
\text { con acceso } \\
\text { exterior }\end{array}$ & $\begin{array}{l}\text { Focalización } \\
\text { externa }\end{array}$ & $\begin{array}{l}\text { Omnisciencia } \\
\text { neutral }\end{array}$ & Heterodiegético \\
\hline $\begin{array}{l}\text { Cinco días } \\
\text { secuestrada, } \\
\text { cinco días de } \\
\text { infierno }\end{array}$ & $\begin{array}{l}\text { Empleo de } \\
\text { la primera } \\
\text { persona y } \\
\text { ángulo simple }\end{array}$ & $\begin{array}{l}\text { Focalización } \\
\text { interna }\end{array}$ & Yo como testigo & Autodiegético \\
\hline $\begin{array}{l}\text { Chicas } \\
\text { Kaláshnikov }\end{array}$ & $\begin{array}{l}\text { Empleo de } \\
\text { la primera, } \\
\text { segunda y } \\
\text { tercera persona } \\
\text { con ángulo } \\
\text { simple y } \\
\text { omnipresente }\end{array}$ & $\begin{array}{l}\text { Focalización } \\
\text { interna y } \\
\text { focalización } \\
\text { externa }\end{array}$ & $\begin{array}{l}\text { El Yo como } \\
\text { testigo y } \\
\text { omnisciencia } \\
\text { neutral }\end{array}$ & $\begin{array}{l}\text { Autodiegético, } \\
\text { homodiegético y } \\
\text { heterodiegético }\end{array}$ \\
\hline $\begin{array}{l}\text { Carta desde } \\
\text { Durango }\end{array}$ & $\begin{array}{l}\text { Empleo de } \\
\text { la primera } \\
\text { y la tercera } \\
\text { persona con } \\
\text { ángulo simple y } \\
\text { omnipresente }\end{array}$ & $\begin{array}{l}\text { Focalización } \\
\text { interna y } \\
\text { externa }\end{array}$ & La mayoría & $\begin{array}{l}\text { Omnisciencia } \\
\text { neutral y el yo } \\
\text { como testigo }\end{array}$ \\
\hline
\end{tabular}

Fuente: Elaboración propia

\section{Análisis de resultados y discusión}

\section{Las figura del autor-cronista y el narrador periodístico- literario}

Una vez abordados los postulados teóricos respecto del tema se procede a un análisis empírico. En este punto es conveniente recalcar que la variedad de puntos de vista y la diversidad de los tipos de narradores construidos pueblan las crónicas que se difunden a diario. Para ejemplificar los criterios anteriormente expuestos realizamos un análisis de 
las crónicas de Alejandro Almazán y nos detendremos, justamente, en la forma en que este autor construye a sus narradores. El siguiente es el inicio de su texto "Carta desde La Laguna" de Almazán (2013):

Nunca has caminado por el Cerro de la Cruz, pero por la manera en que el guía llama al lugar, "la Pus de La Laguna", sabes que inspira miedo el mero hecho de nombrarlo. Apenas subas, te darás cuenta de que, en vez de trepar hacia el cielo, bajarás hacia el infierno (p. 1).

Se trata de un relato en segunda persona e ingresa en el ítem dos de la clasificación de Saavedra Vergara (1999). Para Genette (1989), en cambio, recae en el ámbito de la focalización interna, porque la narración se hace en el interior de la historia y para Friedman (1975) hay una omnisciencia selectiva, porque la historia gira en torno a un único personaje. Se trata de un personaje clave para el desarrollo de la crónica.

En este texto, Almazán ha preferido optar por un narrador que en cierta manera confronte al lector y lo interpele con el uso de esa segunda persona, un componente que se convierte en clave para guiar al lector por los vericuetos de los acontecimientos que cuenta. Para Aren et al. (2016), el rol del narrador en el periodismo literario es clave para comprender lo que el autor se dispone a relatar; su elección no es gratuita, sino que responde a determinados criterios que el periodista pensó con suficiente antelación.

En otra crónica de Almazán (2008), titulada "Los Acapulco Kids", el autor se vale de un narrador diferente al anterior para empezar su historia:

La primera vez que Jarocho me ofreció a una niña por 300 pesos le dije que sí, que a eso había ido al Zócalo aquella noche. El tipo, que cuidaba autos frente al Malecón, se echó la franela al hombro y sonrió de tal manera que los dientes le brillaron en el oscuro rostro, reventado por el acné. Luego, cuando se dispuso a traerla de un callejón, dije que no, que mejor volvería más tarde (p. 1).

Este es un inicio clásico en el ámbito de la crónica. El autor apela al uso de la primera persona para contar una historia sobre la prostitución infantil. En palabras de Friedman (1975) hay el predominio del yo como testigo y según Genette (1989) existe una focalización interna por cuanto el narrador es, al mismo tiempo, un personaje del relato. Para autores como Garza (2003), el empleo de este tipo de narrador es contraprodu- 
cente y agrega que "solo podría resultar eficaz si se explica la historia de un modo que sería imposible contar con una simple enumeración directa de los hechos, lo cual permitiría por otra parte crear una tensión dramática" (p. 47). En cambio, desde la perspectiva de Maidana (2016), el uso de la primera persona constituye una herramienta gramatical válida para generar mayor impacto e incrementar un interés más elevado en el lector. Adicionalmente, se trata de "una combinación entre trabajo de campo (mirar, entrevistar, recorrer) y documentación (buscar qué se ha dicho, qué se ha escrito, qué cifras hay que enriquezcan con datos lo que se va a contar y lo ancle a la realidad)" (p. 30). Este criterio queda evidenciado en la crónica analizada. Más adelante, en el mismo trabajo, el autor intercala el empleo de la primera persona con experiencias personales sucedidas en el transcurso de la reportería. Estas experiencias personales son significativas en el desarrollo de la historia.

Empecé a sudar y me sentí pegajoso. Lo único que se me ocurrió fue acelerar. Tan preocupado iba que pasé los semáforos en rojo. Entonces ahí sí me detuvo la policía. Bajé del auto y, entre murmullos, les tuve que decir que era reportero y que la niña era parte de la historia. Uno de ellos, el de mandíbulas potentes, le echó la luz a Allison y ella sonrió de tal manera que en ese momento hubiese podido venderle cocaína a cualquier cártel. "Pues si ya le pagaste, cógetela", dijo el oficial y yo quise romperle la cara (p. 5).

Según Wolfe (1976), estos recursos son válidos en la medida en que se presentan los hechos desde la perspectiva de un personaje que se encuentra implicado también en la historia y, por lo tanto, el relato dejó de ser impersonal y se destaca porque seduce la atención del lector. En todo caso, el empleo de la primera persona es uno de los rasgos de la mayoría de las crónicas y un atributo que no puede darse en géneros tradicionales como la noticia, por ejemplo.

En la siguiente crónica denominada "Lino Portillo, asesino a sueldo" se denota el uso de un narrador que, en palabras de Friedman (1975), aplica la omnisciencia neutral. Es un recurso propio de la literatura, de los cuentos y novelas, principalmente, pero que se ha empleado en textos como el que se lee a continuación de Almazán (2003):

Al final de esta historia Lino Portillo Cabanillas se quedará solo, enfurecido y con la idea de que lo van a matar. Pero eso sucederá 
hasta el final porque en estos momentos, esta noche de jueves 6 de febrero de 2003, apenas le están informando que un juez le dictó el auto de formal prisión. Le dicen que el homicidio no se libra solo con una fianza. Por las maldiciones que arroja para sus adentros y por ese sabor a cobre que dice tener en el paladar, pareciera que lo acaban de desahuciar (p. 1).

Como se aprecia, este tipo de narrador lo sabe todo, incluso lo que ocurre antes y después; se mueve a su antojo por cada uno de los sucesos que integran la historia y la cuenta como lo desea. Además, tiene acceso a lo que piensa el personaje. Por ejemplo, Almazán en su texto señala las "maldiciones" que Lino Portillo arroja para sus adentros. ¿Cómo es eso posible? Para Saavedra Vergara (2000), estas facultades o prerrogativas cognoscitivas no son patrimonio de los narradores de ficción y en el periodismo literario su aplicación depende de que se apoyen en una intensa investigación. "Sobre la base de entrevistas en profundidad, en las que se preguntaba justamente sobre los sentimientos y pensamientos, el periodista podía luego inferir el estado mental de su personaje" (p. 169).

Este mismo criterio se aplica en la crónica titulada "Cinco días secuestrada, cinco días de infierno" de Almazán (2010), pero en este caso se da lo que Genette (1989) llama focalización interna, por cuanto es un personaje quien cuenta la historia. Veamos:

Otra noche de insomnio y de espanto: otros de la banda, inestables y brutales, empezaron a golpear a un joven; escuché su llanto. En eso entró Chavo muy agitado y me dijo que me pusiera a rezar con él, porque sus compañeros estaban drogados y ya habían matado a un secuestrado. Dejé de rezar después de varias horas cuando escuché a El Loco: “¿Buenos días, mi amor, qué quieres de desayunar?". El desayuno fue una violación (p. 1).

Se trata de un fragmento que impacta y procura no dejar indiferente al lector. En términos de Saavedra Vergara (1999), es la descripción de un ángulo simple, porque se cuentan las experiencias de un determinado personaje, en este caso la mujer secuestrada y violada. Pese a lo eficaz que se considere este recurso para atraer la atención del lector, algunos estudiosos como Chillón (1999) lo cuestionan debido a que consideran que no debe existir en el periodismo ninguna vía de acce- 
so a lo que piensan los personajes de una historia. “¿Cómo podrá el reportero, pues, acceder a los pensamientos de alguien sin poner en severo entredicho la esencial condición documental de su trabajo?" (p. 282). Para Grijelmo (1997), en cambio, un relato vivido que entra en el ámbito de lo experiencial, como el anterior, puede proceder de lo que denomina citas en estilo directo y así evitar cuestionamientos que podrían poner en entre dicho la veracidad del escrito.

El siguiente fragmento pertenece a la crónica "Chicas Kaláshnikov" de Almazán (2011). En ella el narrador sale y entra de la historia alternando la primera, segunda y tercera persona. Leamos:

Por lo pronto, les cuento que Yaretzi llegó al patio de la prisión conducida por una custodia que se sentía más grande que las tinieblas. "Solo quiero saber cómo funciona tu mundo", le dije a Yaretzi, y ella entendió que el tipo que tenía enfrente no había venido a visitarla para resolver los asesinatos. Aceptó y luego pidió una sola cosa, como si buscara la redención: "Debes escribir que creo en Dios y que estoy arrepentida”. Así será. Pero primero hay que empezar cuando ella trabajaba para el Diablo (p. 1).

En esta primera parte hay un narrador bien diferenciado que se dispone a contar la historia. En palabras de Genette (1989) sería un narrador autodiegético, porque es a la vez personaje y se sitúa en un instante posterior al relato. Para estudiosos como Gil (2006), la construcción del narrador es un empleo de carácter retórico que no debe reñir con la ética, pues se trata de una historia expresada en clave netamente periodística y, por tanto, apegada a los hechos, porque "tanto el yo-narrador como el narrador (encubierto)-personaje adquieren relieve, dimensión y un contorno definido a medida que se avanza en la lectura de las crónicas" (p. 349).

En este mismo texto, "Chicas Kaláshnikov", hay un cambio inusitado de narrador, de la primera persona a la segunda, y se da un proceso de focalización interna, según Genette (1989), por cuanto la narración se hace desde el interior de la historia. Veamos:

Llegas a aquella pira de llantas y lo primero que ves incendiándose es la cabeza de tu hermano. Quienes lo asesinaron no se han conformado con decapitarlo. Entonces terminas empotrada a la tierra y lloras como si quisieras llorarle para siempre. Tú se lo ad- 
vertiste: "No te metas, estás muy morro y las armas las maneja el Diablo". "Pero tengo güevos", te contestó. "Aquí no hay que tener güevos, sino odio por la gente", le dijiste, y a él le importó un carajo tu consejo. Ahora está muerto, partido en dos, y tú acordándote, sabe por qué, de aquella narcomenudista, la que mataste para graduarte como sicaria. Fue cuando tenías veintiún años. Acuérdate, Yaretzi. Fue el mero día de las madres. Desde que la viste treparse a su carro la querías matar. Esa vieja fue la que anduvo diciendo en el barrio que tú eras una puta y todos, hasta tu marido, le creyeron. Ella, siempre lo dices, arruinó tu vida. Si un día hasta te aventó a la policía. Y mira lo que fueron las cosas: te ordenaron matarla (p. 2).

Aparte del dinamismo que se pretende dar a la crónica, el trato que el autor le da con la construcción del narrador tiene como propósito mostrar una visión holística de los hechos. Es difícil, pero es uno de los postulados básicos de toda forma de hacer periodismo, aunque se cumpla, muchas veces, solo en teoría. A criterio de Sotolongo (2007) no es una casualidad "la integración lograda entre las formas elocutivas, como tampoco que los periodistas hayan empleado el enfoque múltiple en la elección del narrador, es decir, la combinación del heterodiegético con el homodiegético, y del primero con el autodiegético" (97). Y añade que con esta alternante construcción narrativa el autor orienta su texto hacia un carácter original que es su forma de asumir el relato periodístico. Esa originalidad también está presente en el inicio de la crónica "Carta desde Durango" de Almazán (2011):

Las moscas que atraen los doscientos treinta y ocho cadáveres vuelan alrededor de nuestros rostros. El forense las maldice e intenta ahuyentarlas. Falla. Están hambrientas y no dejarán pasar aquel festín de carne podrida. Frente al olor tampoco lograremos mucho. Parece no haber tapabocas que contenga esa miasma que espanta, que desfonda. En algún momento le diré al forense que me siento pesado como si fuera uno de esos muertos que, desde abril, empezaron a brotar del subsuelo, quizá buscando su nombre, quizá buscando quién les rece un rosario. Él, con esa cara trabajada de quien ha asumido que la vida y la muerte no están en sus manos, apenas hace un guiño y se trepa a una de las dos cajas refrigeradas 
del tráiler donde la policía arrumbó a los difuntos como reses en carnicería. "Orita van a venir por este", me dice y abre ligeramente el costal. Yo solo veo un esqueleto pelado por los gusanos (p. 1).

Narrada en sus primeras líneas en tercera persona, el texto recae en la omnisciencia neutral indicada por Friedman (1975) porque el narrador, al parecer, utiliza un modo impersonal; sin embargo, posteriormente, hay un salto hacia la primera persona cuando en el relato se inmiscuye el yo autodiegético que señala Genette (1989). Un estudio de Fernández (2013) indica al respecto que en el plano eminentemente periodístico, la figura del narrador debe preocuparse por elaborar el contexto de la historia con el propósito de que la construcción narrativa en el relato periodístico adquiere rasgos de verosimilitud y, al mismo tiempo, se amplían las "prerrogativas cognoscitivas" (Saavedra Vergara, 1999) existentes en la crónica.

\section{Conclusiones}

A lo largo de este trabajo hemos podido evidenciar que la construcción del narrador no es una figura exclusiva en los textos literarios, sino que también está presente en los géneros periodísticos y, particularmente, en la crónica. Para ello, y para ejemplificar lo dicho, hemos analizado cómo esta creación se elabora y se recrea en los textos seleccionados del autor mexicano Alejandro Almazán.

La revisión bibliográfica realizada en este trabajo, que no es exhaustiva pero sí significativa, sirve también para demostrar que la escasa atención que se ha prestado a este tipo de temas investigativos requiere un abordaje de los estudios literarios. Y ello porque tanto los problemas de punto de vista como de construcción narrativa son aspectos fundamentales para entender la estructura que tienen textos como las crónicas. Esta comprensión es relevante además porque se puede dotar de mayor sentido y significación a la producción periodístico-literaria.

Hay un largo camino en los estudios relacionados con la construcción del narrador de no ficción. Este es solo un aporte en los estudios periodísticos, porque combatir la orfandad teórica a la que hemos hecho referencia aún es un desafío que se tiene por delante. 


\section{Referencias bibliográficas}

Aguilar, M. (2018). La crónica latinoamericana actual como género y como discurso [Tesis de doctorado no publicada]. Pontificia Universidad Católica de Chile, PUC.

Almazán, A. (2008). Los Acapulco Kids. Revista Emeequis, (148), 28-35.

Almazán, A. (2018). Chicas Kaláshnikov. Revista Gatopardo, (118), 4552. Publicado originalmente en 2011.

Almazán, A. (2011). Carta desde Durango. Revista Gatopardo, (123), $16-22$.

Almazán, A. (2013). Carta desde La Laguna. Revista Gatopardo, (139), 46-52.

Almazán, A. (12 de febrero de 2010). Cinco días secuestrada, cinco días de infierno. Diario El Universal. https://cronicasperiodisticas.wordpress.com/2010/02/12/cinco-dias-secuestradacinco-dias-de-infierno/

Almazán, A. (9 de febrero de 2003). Lino Portillo, asesino a sueldo. Diario El Universal. https://archivo.eluniversal.com.mx/nacion/93280.html

Aren, F., Cano, F., y Vernino, T. (2016). La crónica no ficcional: la mirada del cronista y el narrador. Question, (1), 12-28.

Barthes, R., Greimas, A. J., Bremond, C., Gritti, J., Morin, V., Metz, C., Todorov, T., y Genette, G. (1998). Análisis estructural del relato. Ediciones Coyoacán.

Benavides, J. (2016). Procedimientos narrativos, procesos creativos y de producción de los cronistas ecuatorianos en las revistas de periodismo literario. Un estudio de los casos Mundo Diners, SoHo y Gatopardo [Tesis de doctorado no publicada]. Universidad Nacional de La Plata.

Chatman, S. (1990). Historia y discurso: la estructura narrativa en la novela y en el cine. Taurus.

Chillón, A. (1999). Literatura y periodismo. Una tradición de relaciones promiscuas. Aldea Global.

Falbo, G. (2007). Tras las huellas de una escritura en tránsito. Al margen.

Fernández, R. (2013). El prólogo de Operación Masacre de Rodolfo Walsh: el literato/escritor y el periodista/investigador. La Trama de la Comunicación, (1), 131-149.

Friedman, N. (1975). Form and meaning in fiction. University of Georgia Press. 
Gargurevich, J. (1982). Géneros periodísticos. Ediciones Ciespal.

Garza, C. (2003). Vigencia del relato como sentido de la realidad: análisis de reportajes históricos [Tesis. Universidad Complutense de Madrid.

Genette, G. (1989). Figuras III. Lumen.

Gil, J. (2006). La crónica periodística de Antonio Díaz-Cañabate. Desde la crónica impresionista hasta su consolidación como fenómeno mediático [Tesis de doctorado no publicada]. Universidad de Sevilla.

Grijelmo, Á. (1997). El estilo del periodista. Taurus.

Hoyos, J. (2003). Escribiendo historias. El arte y el oficio de narrar en el periodismo. Universidad de Antioquía.

Maidana, S. (2016). La crónica narrativa latinoamericana como género híbrido. Los modos de construir la voz propia: el caso de Leila Guerriero [Tesis de licenciatura no publicada]. Universidad Nacional de Rosario.

Martínez, T. (26 de octubre de 1997). Periodismo y Narración: Desafíos para el siglo XXI. https://revistas.javeriana.edu.co/index. $\mathrm{php} /$ cualit/article/view/7993

Puerta, A. (2016). La crónica latinoamericana actual: lo maravilloso real. Análisis del periodismo narrativo de Alberto Salcedo Ramos [Tesis de doctorado no publicada]. Universidad Autónoma de Madrid.

Ricoeur, P. (2005). Lenguaje, texto y realidad. Biblos.

Rotker, S. (1992). La invención de la crónica. Fondo de Cultura Económica.

Rossman, G. y Rallis, S. (1998). Learning in the field. An introduction to qualitive research. Sage.

Saavedra Vergara, G. (1999). Voces con poder. Estrategias para hacer más elocuente y creíble al narrador de no ficción periodística [Tesis de doctorado no publicada]. Universidad Autónoma de Barcelona.

Saavedra Vergara, G. (2000). La narrativización del discurso y el efecto omnisciente en no ficción periodística. Caplletra, (29), 157172. https://dialnet.unirioja.es/servlet/articulo? codigo $=227$ 2084\&orden $=0$ \&info $=$ link

Sotolongo, D. (2007). Reportajes de las Páginas Especiales de Escambray: enfoque crítico a la calidad periodística [Tesis de licen- 
ciatura no publicada]. Universidad Central "Marta Abreu" de Las Villas.

Stanzel, F. (1984). A theory of narrative. Cambridge University Press.

Turco, L. (1989). Dialogue. A Socratic dialogue on the art of writing dialogue in fiction. Writer's Digest Books.

Vasilachis, I. (2006). Estrategias de investigación cualitativa. Editorial Gedisa.

Wolfe, T. (1976). El nuevo periodismo. Anagrama. 